Прекаризация труда как растущая форма занятости молодых специалистов в условиях пандемии ${ }^{1}$

Пандемия стала катализатором неизбежного процесса цифровизации коммуникаций, стремительно изменив организацию и технологии реализации профессиональной деятельности миллионов сотрудников по всему миру. Рост безработицы, перевод всех возможных профессиональных групп на дистанционную работу, обусловленные внешней необходимостью в изоляции для минимизации распространения в 2020 году Covid-19, ведут к радикальному изменению рынка труда. Поиск ответов на новые вызовы дерегуляции трудовых отношений возможен путем изучения процессов прекаризации на рынке труда. Научный интерес представляет изучение участия в этих процессах молодежи, которая восприимчива к социальным инновациям и обладает высокими компетенциями в информационных технологиях. Исследование профессиональных траекторий выпускников вузов, трудоустроенных в Уральском регионе и за его пределами, позволяет выявить, могут ли быть успешны формы прекарной занятости на рынке труда, каковы характеристики вовлеченных в эти формы социальных групп. Авторы используют мониторинг выпускников вуза 2017-2019 г2., проведенный на основе опросных и административных данных. Для обработки информации использованы методы классификации, экспертных оценок. Анализ показал, что 34,4 \% выпускников вуза относятся к прекариату, из них лишь 8,8\% - безработные. Молодые специалисты, занятые в форме фриланса и в сфере IT-технологий, успешно трудоустроены, имеют высокие показатели трудоустройства по специальности, заработной плате, удовлетворенности работой. Результаты применимы для балансировки неустойчивой занятости и использования ее лучших практик, накопленных фрилансерами и специалистами в сфере IT-технологий, как социального инструмента регулирования трудовых отношений в сложной эпидемиологической ситуации.

Ключевые слова: прекаризация, прекариат, фрилансеры, неполная занятость, IТ-специалисты, иностранные студенты, неустойчивая занятость в условиях пандемии, рынок труда, трудоустройство, выпускники вуза, молодые специалисты, профессиональные траектории, финансовая успешность, высшее образование

\title{
Благодарность
}

Исследование поддержано программой 211 Правительства Российской Федерации, контракт № 02.A03.21.0006.

Для цитирования: Кокшаров В. А., Агарков Г. А., Сущенко А. Д. Прекаризация труда, как растущая форма занятости молодых специалистов в условиях пандемии // Экономика региона. 2020. Т. 16, вып. 4. С. 1061-1071. https://doi. org/10.17059/ekon.reg.2020-4-4

\footnotetext{
1 () Кокшаров В. А., Агарков Г. А., Сущенко А. Д. Текст. 2020.
} 
Viktor A. Koksharov a), Gavriil A. Agarkov ${ }^{\text {b) }}$, Anastasia D. Sushchenko ${ }^{\text {c) }}$

a, b, c) Ural Federal University, Ekaterinburg, Russian Federation

b) http://orcid.org/0000-0002-6533-3557,e-mail: g.a.agarkov@urfu.ru

c) http://orcid.org/0000-0003-0273-4422

\section{Precarisation of Labour as a Growing Form of Employment of Young Specialists in the Context of the Covid-19 Pandemic}

The Covid-19 pandemic has catalysed the inevitable digitalisation of communications and rapidly changed the organisation and technologies of professional activities of millions of employees worldwide. The growth of unemployment, the transition of professional groups to remote work (wherever possible) due to the need for isolation to minimise the spread of COVID-19 in 2020 led to radical changes in the labour market. Studying the processes of precariation can facilitate the search for responses to new challenges related to deregulation of labour relations. We are interested in examining the participation of youth in these processes. Young population is receptive to social innovation and has excellent competencies in the field of information technology. An analysis of professional trajectories of university graduates (employed in the Ural region and beyond) helps identify whether precarious employment in the labour market can be successful, and determine the characteristics of social groups involved. We used the monitoring of university graduates conducted in 2017-2019 based on survey and administrative data. To process the data, we applied the methods of classification and expert evaluations. The analysis showed that $34.4 \%$ of university graduates belong to the precariat, with only $8.8 \%$ being unemployed. Young freelancers and IT-professionals are successfully employed, satisfied with their jobs and high salaries, demonstrating high rates of employment in their specialty. The results can be applied for balancing precarious work; its best practices, accumulated by freelancers and IT-professionals, can be used as a social tool for regulating labour relations in an unfavourable epidemiological situation.

Keywords: precarisation, precariat, freelancers, underemployment, IT professionals, foreign students, precarious employment during the Covid-19 pandemic, labour market, employment, university graduates, young professionals, professional trajectories, financial success, higher education

\section{Acknowledgments}

The article has been prepared with the support of the Act 211 of the Government of the Russian Federation, the contract No. 02.A03.21.0006.

For citation: Koksharov, V. A., Agarkov, G. A. \& Sushchenko, A. D. (2020). Precarisation of Labour as a Growing Form of Employment of Young Specialists in the Context of the Covid-19 Pandemic. Ekonomika regiona [Economy of region], 16(4), 1061-1071, https://doi.org/10.17059/ekon.reg.2020-4-4

\section{Введение}

В контексте неопределенности условий рынка труда и безработицы среди части трудоспособного населения наряду с формальной занятостью появляются формы неустойчивой занятости. Вплоть до 2020 г. эти формы трудовых отношений рассматривались экономистами, социологами, исследователями рынка труда как ненадежные, нестабильные, ограничивающие возможности самореализации личности, негативно влияющие на социальное самочувствие социальных групп.

Ключевым вызовом в марте - апреле 2020 г. стала непрогнозируемая ситуация вспышки короновирусной инфекции, парализовавшая развитие производств, предоставление услуг, требующих непосредственного взаимодействия субъектов, сократила возможности сбыта производимой продукции. Одной из острых социальных проблем является необходимость регулирования социально-экономических взаимодействий, региональных рынков труда.

В сжатые сроки миллионы сотрудников компаний оказались в числе прекари- ата. Режим самоизоляции привел к резкому росту безработицы, сокращению заработных плат сотрудников, изменению организации повседневных практик трудовой деятельности. Другой стороной пандемии выступает мотивация личности к действиям в силу замкнутой, статичной социальной жизни. ${ }^{1}$ Единовременного возврата к предпандемическому положению не произойдет, и формы дистанционного взаимодействия будут чрезвычайно востребованы.

Прекарии действуют как агенты в пространстве нестабильности и незащищенности рынка труда и социальной жизни. В условиях пандемиии происходит парадоксальная ситуация: уязвимый класс прекариата оказывается более «защищенным», чем работники, имеющие опыт только формальной занятости. Выявление профессиональных характеристик прекариата, трансляция его позитив-

\footnotetext{
${ }^{1}$ How to Maintain Motivation in a Pandemic. The New York Times. URL: https://www.nytimes.com/2020/05/18/well/mind/ motivation-pandemic-coronavirus.html (дата обращения: 22.05.20).
} 
ного опыта адаптации к неопределенности могут способствовать снижению социальной напряженности среди групп с высоким риском прекаризации.

\section{Обзор литературы}

С исторической точки зрения прекариат возник в период 1975-2008 гг., когда происходило формирование и развитие глобальной рыночной экономики, основанной на конкурентоспособности и индивидуализме [1, с. 2]. Ключевой характеристикой институциональных изменений рынка труда стала практика гибкости трудовых отношений.

По мнению британского экономиста Гая Стандинга, в условиях мирового экономического рынка XXI в. прекариат (от слов «ненадежный» и «пролетариат») занимает уязвимое положение в обществе. Прекариат представляет социально-экономическую группу, у которой отсутствуют гарантии сохранения работы (кроме прав на получение оплаты за текущий труд), социальные гарантии в виде пособий по безработице [1, с. 7-12], медицинское страхование.

В 1998 г. французский социолог П. Бурдье ввел в научный оборот термин «flexploitation», подразумевающий «рациональное управление отсутствием безопасности, которое посредством согласованных манипуляций с производством создает конкуренцию между рабочими в странах с наибольшими социальными выгодами» [2, с. 85]. Политические факторы и социально-экономические последствия формирования прекариата становятся ведущими, за счет управления рабочими ресурсами работодатели получают возможности снижать издержки производства. Незащищенность, гибкость трудовых отношений касается молодых специалистов. На старте карьеры они вынуждены формировать профессиональные траектории в условиях отсутствия опыта в профессии и компенсировать это снижением требований к будущее работе: временная занятость, низкие заработные платы, скромные социальные преимущества.

Прекариат повышает финансовую независимость работника от конкретного работодателя, но глобально способствует повышению дисциплинированности рабочей силы [3]. Общепризнана роль глобализации в увеличение объема прекариата во всем мире. Авторы [4] констатируют: это новая тенденция на Западе, но давняя реальность для остального мира (в Китае неформальная работа - не новое явление, а норма еще с ранней индустриализации Китая 1898-1949 гг.).

Повсеместная неформализация занятости и сокращение коллективного потенциала трудящихся затруднят защиту прав работников в трудовых спорах с работодателями [5]. В работах зарубежных ученых внимание уделяется вопросам защиты прав работников по прекарной форме занятости. Необходимо объединить понятия неформальной и нестандартной занятости и сформировать механизмы социальной защиты вне зависимости от форм занятости [6]. Исследователи [7, 8] отмечают, что прекаризация приводит к появлению новых форм самоорганизации трудящихся, что влечет социальные и экономические последствия.

Значительное внимание социологи и экономисты уделяют специфике прекариата в различных сферах деятельности. Широкое распространение он получил в высшем образовании. К причинам такой ситуации (в [9] - на примере Ирландии) относят сокращение бюджетов, передачу финансирования научных исследований внешним агентствам, сокращение постоянных контрактов и увеличение использования неполного рабочего дня, временных сотрудников для преподавательской и исследовательской работы. Неолиберализация университетов резко изменила характер занятости в учреждениях. Постоянные рабочие места сокращаются в пользу временной работы. Основываясь на анализе академической трудовой практики в ирландском высшем образовании, авторы приходят к выводу, что прекаризация стала системной, а не только прерогативой ученых без степени или с малым опытом научной работы. По их мнению, это следствие мер строгой экономии на расходах на высшее образование и науку.

Развивается тенденция расширения прекариата в школах [10], по такой схеме в международных средних англоязычных школах в неанглоязычных странах к 2022 г. будет работать более полумиллиона преподавателей, главным образом из США и Великобритании. В то же время обсуждается и роль образования в управлении социальным риском, создаваемым прекариатом [11].

Специфика работы молодых работников умственного труда рассмотрена в [12] на примере ситуации в Италии. Работников часто позиционируют как «независимых профессионалов», хотя они все чаще сталкиваются с условиями, аналогичными условиям постоянных работников, и острее страдают от последствий кризисов в результате расширения прекариза- 
ции в отсутствии поддержки профсоюзов и политического представительства.

«Уберизация» экономики рассматривается учеными как один из наиболее значимых факторов, способствующих росту прекариата. Интересно рассмотрение организации труда uber-таксистов [13]. Прекаризации подвержены практически все сферы деятельности, в частности, ученые в области исследований мобильности [14] отмечают профессиональный спорт.

Широко представлены российские исследования процесса прекаризации, исследователи ищут причины роста нового социального класса [15]. В работе [16] исследуется неустойчивость рынка труда в государственном секторе, являющейся причиной прекаризации для социально ориентированных профессий в российских мегаполисах.

Посредством кластерного и факторного анализа, построения модели вероятности включения в прекариат (логит-модель) авторами [17] сделан вывод, что к этой категории может быть отнесено уже до $27 \%$ работающих россиян. Исследователи отмечают «расширение вынужденных для работника социально-экономических отношений занятости» [18, с. 672]. Работа перестает служить источником средне- и долгосрочного планирования.

При изучении содержательных характеристик прекариата исследователи в области экономики образования доказывают, что среди самозанятых работников в области науки и техники существуют «большие штрафы» в заработной плате за несоответствие работы полученному высшему образованию, это обстоятельство не снижает уровень удовлетворенности ими работой. Причины несоответствия работы высшему образованию среди самозанятых сильно различаются по полу» [19, с. 85]. Углубленное изучение удовлетворенности прекариев работой может изменить сформированные об этом классе представления.

Расширение исследований прекариата за счет применения теории детерминации дает преимущество: «При осуществлении стратегий трудоустройства выпускники вузов руководствуются возникшими во время обучения ценностными ориентациями, определяющими выбор той работы, которая обеспечит реализацию имеющихся знаний, умений, желаемый доход, профессиональный и карьерный рост» [20, с. $123-124]$.

Авторы настоящей статьи к прекариату относят как занятых несамостоятельным трудом (наемных работников, в том числе специ- алистов в сфере IT-технологий как социальной группы, обладающей рядом специфических характеристик профессиональных траекторий), занятых на неполный рабочий день, так и лиц, занятых самостоятельным трудом.

В исследовании в качестве прекариата рассматриваются выпускники вуза через полгода после его окончания, являющиеся мобильной социальной группой, потребности в реализации профессиональных траекторий которой обусловлены внутренней необходимостью - в уточнении индивидуальных склонностей к профессии, и внешней - общественной потребностью в квалифицированных кадрах, обладающих самоорганизованностью, умениями решать задачи в условиях неопределенности и гибкости общественной и трудовой деятельности.

Среди типов прекарной занятости, выделяемых экономистами и социологами $[18 ; 21$, c. 62-66], мы рассматриваем те, которые применимы к характеру трудовых отношений между работодателями и выпускниками вузов.

1. Фрилансеры как представители «креативных профессий».

2. Занятые в сфере IT-технологий - специалисты по информационным технологиям, программисты и др.

3. Имеющие занятость на неполный рабочий день, нерегулярные приработки - форма занятости, скрывающая масштабы безработицы; люди работают больше и получают за труд меньшее вознаграждение.

4. Вовлеченные в профессиональную деятельность на аутсорсинге.

5. Мигранты. В нашем исследовании - иностранные студенты, трудоустроенные на российском рынке труда (им легче интегрироваться на рынок труда, высшее образование является полем для мягкой интеграции в культуру страны).

6. Безработные как прекариат. Показатели безработных некорректно интерпретировать без вычета продолжающих обучение в магистратуре других вузов, аспирантуре или осваивающих дополнительное образование. Инвестиции в человеческий потенциал приносят большую отдачу в долгосрочной перспективе, чем быстрая интеграция на рынке труда.

7. Смешанный тип, включающий характеристики первых пяти типов.

Первые две группы «представляют трудно подвергающуюся учету социальную группу так называемых креативных профессий. Их нередко пытаются представить привержен- 
цами свободолюбивого духа, независимых от строгой и мелочной регламентации официальных предприятий и организаций» [21, с. 65]. Отличием занятых в сфере IT-технологий от фрилансеров является то, что лица в данной профессиональной области могут иметь весьма устойчивые трудовые отношения. Однако сам характер выполнения ими трудовых обязанностей (например, разработка информационных систем) подразумевает гибкость, выраженную в минимальных ограничениях (относительно места выполнения задач, времени, не считая контрольных точек по проекту). Сфера IT зачастую заимствует подходы проектного управления, где сотрудники выполняют работу не в рамках текущей деятельности, а вовлечены в проекты компании. В социологической литературе «IT-специалисты рассматриваются в качестве наиболее стабильного в плане гарантий занятости сегмента креативного класса» [22, с. 84] в силу дефицита этих кадров на рынке труда. Сами они с легкостью меняют место работы: работа удовлетворяет, но они стремятся балансировать между компаниями, проектами и профессиональными должностями, не нуждаются в долгосрочных трудовых контрактах. Те, кто имеет устойчивые трудовые отношения, по сути содержания работы и отношения к ней близки к фрилансерам, как следствие, к прекариату. Такое мнение разделяют ученые МГУ имени М.В. Ломоносова [23].

Реализация профессиональных траекторий выпускниками вузов, их трудоустройство является базовой характеристикой социальной структуры современного общества. Поэтому изучение трансформаций типов занятости может позволить углубить понимание процессов прекаризации на рынке труда.

\section{Методы исследования и используемые данные}

Вузы могут внести вклад в сохранение устойчивого развития экономики региона посредством консультирования по вопросам регулирования регионального рынка труда на данных о занятости молодых специалистов в контексте пандемии. Это может быть реализовано вузами, сформировавшими инструменты взаимодействия с выпускниками и системные практики получения от них обратной связи. Если университеты начинают использовать институциональные исследования для реализации стратегических целей, то выстраивают политику вуза, обоснованную на данных, подтверждающих рыночное преимущество среди ведущих национальных университетов, имеющих дело с эпохой COVID-19¹.

Следствием изменений среды трудовых отношений и социальной проблемы неустойчивости рынка труда является углубленное изучение качественных и количественных характеристик занятости молодых специалистов, относящихся к прекариату еще до начала пандемии. Выводы базируются на результатах институциональных исследований выпускников 2017-2019 гг. через полгода после окончания ими вуза, проведенных в Уральском федеральном университете.

Данные получены методом онлайн-опроса и сопоставлены с административными данными. Проведено три волны мониторинга в формате ежегодного опроса. Опрошено в среднем $34 \%$ от выпусков (3872 выпускника за исключением бакалавров и специалистов, продолживших обучение в магистратуре УрФУ). Исследование базируется на лучших практиках организации опросов с целью получения от студентов и выпускников обратной связи за рубежом (в США ${ }^{2}$, Австралии $^{3}$, Китае $^{4}$ ) и в России [24].

Технология опроса подразумевала сбор данных по индивидуальным ссылкам на онлайн-анкету. Принципы для обеспечения надежности и достоверности данных: (1) отклик по опросу - не менее 30 \%, (2) отклик по не менее 80 \% направлений подготовки от генеральной совокупности, (3) отклик по направлениям подготовки - не менее 20 \%.

Основными характеристиками опрошенных являются уровень образования студентов (доля опрошенных студентов бакалавриата и специалитета - 59 \%, доля студентов магистратуры - 41 \%) и форма обучения (очная). Выборка включает 62 \% женщин и 38 \% мужчин. Средний возраст опрошенных бакалавров - 22 года, магистров - 25 лет.

\footnotetext{
${ }^{1}$ Douglass A. D., Chirikov I. Refocusing institutional research on university needs, available at: https://www.universityworldnews. com/post.php? story $=20200518114757175 \&$ fbclid=IwAR0uum exYDGdBq1M_ICqum5NT0NsJS7th1TECy34bxS7tOlpPJyXq kflyJ8 (accessed: 24.05.20).

2 Student Experience in the Research University (SERU) Consortium, available at: https://cshe.berkeley.edu/seru (accessed: 24.05.20).

3 Australian Graduate Survey (AGS), available at: http:// www.graduatecareers.com.au/research/surveys/australian graduatesurvey/ (accessed: 24.05.20).

4 Employment rate of Chinese college graduates remains stable: report, available at: https://www.chinadaily.com. $\mathrm{cn} / \mathrm{a} / 201906 / 16 /$ WS5d0648e3a3103dbf1432875c.html (accessed: 24.05.20).
} 
Ключевые сюжеты инструментария опроса измеряют занятость выпускников (типы, формы и географию занятости, должность, место работы, департамент, специализацию и др.), уровень их заработных плат, образовательный опыт в университете, образовательные траектории после выпуска, интерес к получению дополнительного образования.

Региональный контекст исследования заключается в том, что выпускники университета востребованы и трудоустраиваются не только в Свердловской области (по месту расположения университета), но и в других областях Уральского федерального округа (Челябинской области, Курганской области, Тюменской области, включая ХМАО, ЯНАО). УрФУ является крупнейшим вузом, который обеспечивает подготовку молодых кадров, прежде всего для региона (87\% окончивших вуз). В связи с малой численностью групп прекариата в выборке не представляется возможным выявление различий профессиональных траекторий выпускников вуза по критерию географии трудоустройства, это может стать чрезвычайно ценным и значимым предметом анализа специальных исследований.

Анализ этих данных позволит выяснить ряд важных с научной и практической точки зрения вопросов. (1) Какие возможности регулирования регионального рынка труда существуют в условиях пандемии. (2) Каковы характеристики профессиональных траекторий выпускников вуза, какой позитивный личный опыт имеют будучи прекариатом. (3) Какова доля занятых выпускников вуза, которым можно транслировать позитивный опыт части прекариата, чтобы снизить социальную напряженность в обществе. Произведена оценка реальной и потенциальной прекаризации занятости выпускников в период пандемии. Научная значимость этих результатов состоит в определении изменений в социальной структуре современного общества с учетом нелинейности социальных процессов, оценки экономических мотиваций молодых специалистов на рынке труда с точки зрения поведенческой экономики.

\section{Полученные результаты}

Исследование выявило структуру прекариата на старте реализации выпускниками вузов профессиональных траекторий по основной работе. В числе прекариата - 2,6 \% фрилансеров, 18,9 \% заняты на неполный рабочий день, 20,1 \% - в сфере IT-технологий, 0,5 \% - на аутсорсинге, $1,4 \%$ - иностранные студенты, тру- доустроенные в России, 2,5 \% - смешанный тип (имеет несколько признаков перечисленных групп), 8,8 \% - безработные, еще 7,3 \% также не имею работы, но продолжают обучение в той или иной форме. Столь же высок процент продолжающих обучение среди тех, кто занят на неполный рабочий день (47\%). Профессиональные траектории этих двух групп стоит рассматривать скорее как перспективно успешные, осознающие, что в современном мире требуется непрерывное обучение.

Российские практики исследований о прекариате часто акцентируют внимание на структурных параметрах класса [21], качественные характеристики мало изучены. Рассмотрим, как развиваются профессиональные траектории у молодых специалистов (табл. 1).

Ключевой количественный параметр показывает, что средние заработные платы у прекариев выше, чем у выпускников, трудоустроенных в традиционном формате занятости. Уровень удовлетворенности содержанием работы, условиями труда у фрилансеров и ITспециалистов выше, чем в других группах. Те, кто трудоустроен на неполный рабочий день, имеют существенный заработок, могут увеличить его в случае финансовой необходимости. На старте карьеры финансовые траектории у прекариев можно назвать успешными. Важной чертой прекаризации труда становятся заниженные амбиции относительно развития карьерных траекторий: доля трудоустроенных на руководящие должности низкая, а удовлетворенность должностью высока.

Существенная доля прекариев нашли работу по специальности. Этот показатель по вузу выше средней «профильности трудоустройства выпускников российских вузов, которая находилась и находится на уровне $45-50 \%$ \% [25, c. 38]. Фрилансерами стали как инженеры и гуманитарии, так и экономисты; поэтому фриланс - это сфера, где можно применить навыки различных профилей. Помимо тех, кто обучался информационным технологиям в вузе, IT-сферой заинтересовались инженеры и гуманитарии (по 12 \%). Это те, кто разочаровался в профессии, но, имея качественную базовую подготовку, смог найти новую сферу самореализации.

Профессиональные траектории части прекариата (фрилансеров и специалистов ITиндустрии) показывают, что можно получить позитивный личный опыт. Результаты и удовлетворенность от дистанционной работой во многом зависят от умения планировать рабочий день, способности работать самостоя- 
Характеристики профессиональных траекторий и социально-демографических параметров выпускников вуза

Table 1

Features of professional trajectories and socio-demographic parameters of university graduates

\begin{tabular}{|c|c|c|c|c|c|c|c|}
\hline \multirow[b]{2}{*}{$\begin{array}{c}\text { Характеристика профессиональных траектории } \\
\text { и социально-демографических параметров }\end{array}$} & \multicolumn{7}{|c|}{ Значение параметра по исследованным группам } \\
\hline & 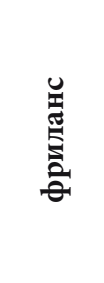 & 疍 & 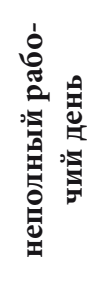 & 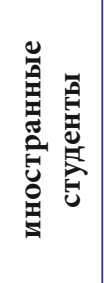 & 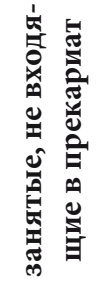 & 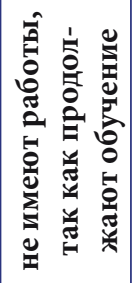 & $\begin{array}{l}0 \\
0 \\
\text { है } \\
\text { है }\end{array}$ \\
\hline \multicolumn{8}{|c|}{ Характеристики профессиональных траекторий } \\
\hline Средняя заработная плата, тыс. руб. & 42654 & 47309 & 27288 & 32199 & 36647 & - & - \\
\hline Доля трудоустроенных на руководящих должностях, \% & 0 & 2 & 6 & 0 & 6 & - & - \\
\hline Наличие подчиненных, \% & 0 & 12 & 11 & 8 & 17 & - & - \\
\hline $\begin{array}{l}\text { Соответствие основной работы специальности } \\
\text { (субъективная оценка выпускников), \% }\end{array}$ & 62 & 76 & 64 & 60 & 72 & - & - \\
\hline \multicolumn{8}{|c|}{ Оиенка удовлетворенности некоторьми параметрами работь } \\
\hline Доля удовлетворенных содержанием работы, \%* & 94 & 86 & 73 & 79 & 76 & - & - \\
\hline Доля удовлетворенных условиями труда, \%* & 82 & 92 & 80 & 81 & 80 & - & - \\
\hline Доля удовлетворенных должностью, \%* & 82 & 85 & 69 & 69 & 74 & - & \\
\hline \multicolumn{8}{|c|}{ Социально-демографические характеристики и образовательные траектории } \\
\hline Доля мужчин, \% & 31 & 50 & 33 & 46 & 37 & 37 & 40 \\
\hline Доля выпускников, окончивших магистратуру, \% & 31 & 51 & 47 & 50 & 44 & 24 & 30 \\
\hline $\begin{array}{l}\text { Окончившие инженерно-технические направления, \% } \\
\text { по столбцу }\end{array}$ & 34 & 12 & 21 & 28 & 39 & 23 & 26 \\
\hline $\begin{array}{l}\text { Окончившие естественнонаучные направления, \% } \\
\text { по столбцу }\end{array}$ & 9 & 4 & 16 & 20 & 11 & 17 & 12 \\
\hline Окончившие гуманитарные направления, \% по столбцу & 34 & 12 & 40 & 30 & 23 & 35 & 32 \\
\hline $\begin{array}{l}\text { Окончившие экономические и менеджериальные направ- } \\
\text { ления, \% по столбцу }\end{array}$ & 20 & 8 & 16 & 4 & 19 & 17 & 23 \\
\hline Окончившие математику и IT-направления, \% по столбцу & 3 & 63 & 7 & 19 & 8 & 8 & 7 \\
\hline Доля отличников и хорошистов, \% & 89 & 83 & 87 & 72 & 83 & 91 & 69 \\
\hline
\end{tabular}

* Удовлетворенность теми или иными параметрами рассчитана исходя из суммы крайних положительных баллов (4 и 5) с учетом опыта анализа данных в схожих зарубежных исследованиях.

тельно, умения решать проблемы, готовности брать на себя ответственность за решение задач. Эти свойства личности востребованы работодателями в современном мире [26, с. 14]. Значимость социальных навыков и личностных качеств в исследовании измерялась косвенно - через оценку спроса на дополнительные образовательные услуги. Среди работающих прекариев немного выше спрос на курсы личностного роста и самоорганизации, чем среди прочих выпускников (7,6 \% и 6,7 \% соответственно). Схожие различия в спросе на курсы по психологии (8,3 \% и 6,3\%), что тоже указывает на потребность в формировании личных качеств, умении выстраивать коммуникации с людьми, а также на курсы ITтехнологий (9,0 \% и 5,6 \%). Прекариат осознает реальную ценность постоянного совер- шенствования личных качеств, социальных навыков.

Оценим структуру занятости выпускников вуза и степень их риска стать прекариатом с учетом кризиса в отраслях в связи с Covid-19 (табл. 2).

Степень риска включения сотрудников ряда отраслей экономики в прекариат оценивались с учетом содержания указов губернаторов областей УрФО на запреты реализации профессиональной деятельности и общей российской ситуации (например, касающейся туризма) методом экспертных оценок исследовательской группы.

Во-первых, при формировании групп, имеющих риски прекаризации, мы исходили из следующей гипотезы: базовые отрасли производства останутся работать без существен- 
Таблица 2

Характеристики профессиональных траекторий выпускников вуза и доля трудоустроенных в отраслях экономики с разной степенью риска включения их в прекариат с учетом последствий Covid-19 (\% по столбцу)

Table 2

Features of professional trajectories of university graduates and the share of employed by economic sectors with varying degrees of risk of being included in the precariat, considering the consequences of COVID-19 (\% in columns)

\begin{tabular}{|l|c|c|c|c|c|}
\hline \multirow{2}{*}{ Состав групп с разной степенью прекаризации } & \multicolumn{3}{|c|}{ Значения показателей по годам } & \multirow{2}{*}{ Средняя } \\
\cline { 2 - 5 } & $\mathbf{2 0 1 7}$ & $\mathbf{2 0 1 8}$ & $\mathbf{2 0 1 9}$ & \\
\hline Занятые Прекариат & 18,2 & 18,1 & 18,8 & 18,4 \\
\hline Безработные по причине того, что продолжают обучение & 7,7 & 7,3 & 6,8 & 7,3 \\
\hline Безработные & 8,6 & 9,4 & 8,3 & 8,8 \\
\hline \multicolumn{1}{|c|}{ Занятье и их степени риска прекаризации при Covid-19 } \\
\hline с низким риском & 29,7 & 30,2 & 32,5 & 30,8 \\
\hline с высоким риском & 16,7 & 17,9 & 15,9 & 16,8 \\
\hline с высоким риском безработицы & 10,2 & 8,4 & 9,0 & 9,2 \\
\hline степень риска не определена & 8,9 & 8,7 & 8,7 & 8,8 \\
\hline
\end{tabular}

“ Респонденты имеют формальную занятость, но не дали ответа о своей сфере деятельности.

ных изменений, несмотря на карантинные меры. Экономическое развитие Уральского региона осуществляется за счет повышения конкурентоспособности промышленного кластера, высока вероятность, что многие отрасли производства будут функционировать как стратегически значимые для региона (попадут в первую волну «карантинных послаблений»). К ним мы отнесли широкий спектр производств, энергетику и природные ресурсы, телекоммуникации и связь, строительство и недвижимость, госслужбу, транспорт (в большей части с расчетом на сохранение грузоперевозок) и логистику (допущение - в силу невозможности отделения ее от услуг на транспорт на уровне базы данных), медицину и фармацевтику, службы экстренного реагирования, услуги ЖКХ, юриспруденцию (например, защита интересов сторон в судебной практике), автомобильный бизнес, услуги по ремонту и обслуживанию, журналистику (например, съемка репортажей, подготовка фотобанка), поддержание ряда коммуникаций в сфере международных отношений. У 30,8 \% выпускников занятость имеет постоянный характер, а риски прекаризации их труда низкие.

Во-вторых, смещение центра тяжести современной экономики в сторону оказания услуг дестабилизирует рынок труда в период пандемии. Это туризм и гостиничный бизнес, авиаперевозки, культура, досуг, искусство, организация массовых мероприятий, розничная торговля, ресторанный бизнес, фитнесцентры, косметология, изготовление рекламной продукции, полиграфия. Выявлено 9,2 \% специалистов - это те, кто имеет высокие риски безработицы как следствие изменившихся принципов взаимодействия субъектов и организации публичных пространств.

В-третьих, существуют сферы деятельности, которые по содержанию труда могли бы быть переведены на дистант. С учетом цифровизации технологий и темпов их развития к ним можно отнести банки, инвестиции, финансы, маркетинг, пиар, рекламу, ту часть торговли, которую возможно осуществлять через интернет-магазины, образование и науку, исследования, моду, дизайн. Специалисты этих сфер имеют высокие риски прекаризации труда, лишены навигации действий, внешних регуляторов мотивации, им приходится работать в условиях размытых границ между рабочим и свободным временем. Их в выборке молодых специалистов - 16,8 \%. Те, кто сумеет успешно воспользоваться опытом прекариата, сможет снизить риски безработицы в перспективе.

Анализ профессиональных траекторий позволяет сделать вывод, что уровень высшего образования (совокупность безработных составляют 30 \% магистров и 70 \% бакалавров) и занятость по специальности, полученной в вузе, позволяют минимизировать риски безработицы даже в условиях нестабильности общества. В то же время в период пандемии происходят структурные изменения, которые меняют характер трудовых отношений и походы к реализации профессиональной деятельности личности, результаты которой зависят как от политических, экономических факторов, так и от сформированности у молодых специалистов социальных навыков, личных качеств, помогающих выстраивать личную навигационную систему действий и траекторий. 


\section{Заключение}

Исследовательской повесткой в контексте пандемии стал вопрос, какими могут быть последствия Covid-19 для высшего образования и рынка труда, в частности для выпускаемых вузами кадров, в фокусе проблем социального неравенства, усиления дифференциации социальных групп, дестабилизации трудовых отношений. Экономистам, социологам, эпидемиологам еще предстоит провести обсуждения и поиск ответов, основанных на доказательных данных, связанных с проблемами, с которыми сталкивается высшее образование и рынок труда на глобальном, региональном и национальном уровнях.

Исследование затрагивает вопросы прекаризации труда и его особенностей реализации личностью профессиональных траекторий: адаптация к неопределенности, «к новому», работа в условиях нестабильности, высокие риски остаться безработными, сформированные навыки самоорганизации, умения работать самостоятельно и решать проблемы. Все эти инструменты могут быть основой для заимствования позитивного опыта удовлетворения общественной потребности в быстрой адаптации к изменившему миру, снижения рисков прекаризации труда. Позитивным в анализе рисков прекаризации труда является вы- вод, что порядка 65 \% выпускников вуза «защищены» от последствий пандемии (трудоустроены в отраслях производства, сферах, связанных с жизнеобеспечением населения (30,8 \%)). Для предотвращения негативных последствий Covid-19 на рынке труда и роста безработицы с 8,8 \% в допандемийный период до 34,8 \% (учтены безработные, сферы с высоким риском безработицы и прекаризации труда) стоит транслировать успешный опыт занятости прекариата тем, у кого произошли изменения в организации трудовых отношений.

В новом витке трансформации общества в период пандемии и после ее окончания можно увидеть не только уязвимость отраслей рынка труда (предпринимательство, услуги), но и изменения в характере труда сотрудников организаций (личный опыт работы вне офиса, «иммунитет» к гибким трудовым отношениям, к поиску новых способов развития успешных финансовых траекторий). Перспективой изучения вопросов прекаризации труда среди молодых специалистов является повышение роли институциональных исследований в российских вузах с целью оперативной корректировки стратегий вузов в период выхода из последствий пандемии, основанного на данных прогнозирования проблем безработицы на региональных рынках труда.

\section{Список источников}

1. Guy Standing. The Precariat: The New Dangerous Class. London : Bloomsbury Academic, 2011. 198 c.

2. Bourdieu P. Acts of Resistance. Against the New Myths of our Time. Cambridge: Polity Press, 2000. P. 108 c.

3. Greer I. Welfare reform, precarity and the re-commodification of labour // Work, Employment \& Society. 2016. Vol. 30, iss 1. P. 162-173. doi.org/10.1177/0950017015572578.

4. Swider S. Informal and precarious work: The precariat and China // Rural China. 2017. Vol. 14, iss. 1. P. 19-41. https:// doi.org/10.1163/22136746-01401002.

5. Lee C. K. Precarization or Empowerment? Reflections on Recent Labor Unrest in China // Journal of Asian Studies. 2016. Vol. 75, iss. 2. P. 317-333. doi.org/10.1017/S0021911815002132.

6. Siegmann K. A., Schiphorst F. Understanding the globalizing precariat: From informal sector to precarious work // Progress in Development Studies. 2016. Vol. 16, iss 2. P. 111-123. doi.org/10.1177/1464993415623118.

7. Lazar S., Sanchez A. Understanding labour politics in an age of precarity // Dialectical Anthropology. 2019. Vol. 43, iss. 1. P. 3-14. doi.org/10.1007/s10624-019-09544-7.

8. Standing G. Understanding the precariat through labour and work // Development and Change. 2014. Vol. 45, iss. 5. P. 963-980. doi.org/10.1111/dech.12120.

9. Courtois A., O'Keefe T. Precarity in the ivory cage: Neoliberalism and casualisation of work in the Irish higher education sector // Journal for Critical Education Policy Studies. 2015. Vol. 13, iss. 1. P. 43-66.

10. Bunnell T. Teachers in international schools: a global educational 'precariat'? // Globalisation, Societies and Education. 2015. Vol. 14, iss. 4. P. 543-559. doi.org/10.1080/14767724.2015.1068163.

11. Doherty C. Edufare for the future precariat: the moral agenda in Australia's 'earning or learning' policy // Journal of Education Policy. 2016. Vol. 32, iss.1. P. 34-47. doi.org/10.1080/02680939.2016.1215534.

12. Armano E., Murgia A. The precariousnesses of young knowledge workers: A subject-oriented approach // Global Discourse. 2013. Vol. 3, iss. 3-4. P. 486-501. doi.org/10.1080/23269995.2013.865313.

13. Hua J., Ray K. Beyond the precariat: race, gender, and labor in the taxi and Uber economy // Social Identities. 2017. Vol. 24, iss. 2. P. 271-289. doi.org/10.1080/13504630.2017.1321721.

14. Agergaard S., Ungruhe C. Ambivalent Precarity: Career Trajectories and Temporalities in Highly Skilled Sports Labor Migration from West Africa to Northern Europe // Anthropology of Work Review. 2016. Vol. 37, iss. 2. P. 67-78. doi: 10.1111/awr.12096. 
15. Тощенко Ж. Т. Прекариат - новый социальный класс // Социологические исследования. 2015. № 6. С. 3-13.

16. Volchik V., Klimenko L., Posukhova O. Socio-economic sustainable development and the precariat: A case study of three Russian cities // Entrepreneurship and Sustainability issues. 2018. Vol. 6, iss. 1. P. 411-428. doi.org/10.9770/ jesi.2018.6.1(25).

17. Шкаратан О. И., Карачаровский В. В., Гасюкова Е. Н. Теория и эмпирический анализ. На материалах опросов в России, 1994-2013 // Социологические исследования. 2015. Vol. 12. P. 99-110.

18. Критерии, вероятность и степень неустойчивости занятости с учетом особенностей российского рынка труда / Бобков В. Н., Квачев В. Г., Локтюхина Н. В., Риччери М. // Экономика региона. 2017. Т. 13, вып. 3. С. $672-683$. doi: 10.17059/2017-3-3.

19. Bender K. A., Roche K. Educational mismatch and self-employment // Economics of Education Review. 2013. Vol. 34. P. 85-95. doi: 10.1016/j.econedurev.2013.01.010.

20. Меренков А.В., Сандлер Д. Г., Шаврин В.С. Особенности изменений ориентаций выпускников бакалавриата на трудоустройство // Образование и наука. 2019. № 21 (10). С. 116-142. https://doi.org/10.17853/1994-5639-2019$10-116-142$.

21. Прекариат. Становление нового класса. М.: Центр социального прогнозирования и маркетинга, 2020.400 с.

22. Флорида Р. Креативный класс. Люди, которые создают будущее. М.: Манн, Иванов и Фербер, 2016. 384 с.

23. Котова С. И. Прекаризация рынка труда — вызов экономики трудовому праву? // Экономика и жизнь. 2017. № 41 (992). URL: https://www.eg-online.ru/article/357991/ (дата обращения: 11.08.2020).

24. Rudakov V., Roshchin S. The impact of student academic achievement on graduate salaries: the case of a leading Russian university // Journal of Education and Work. 2019. Vol. 32, iss. 2. P. 156-180. doi: 10.1080/13639080.2019.1617839.

25. Павлова О.Н., Казин Ф.А., Бутаков Н.А. Профильность трудоустройства выпускников вузов. Анализ данных социальных сетей // Университетское управление. Практика и анализ. 2017. Т. 21, № 3 (109). С. 38-56. doi: 10.15826/umpa.2017.03.036.

26. Developing skills for innovative growth in the Russian Federation / Vasiliev K., Roshchin S., Maltseva I. O., Travkin P. V., Lukiyanova A., Chugunov D., Shulga I., Rutkowski J. J., Cahu P. M., Nellemann S. Washington : World Bank, 2013. $150 \mathrm{p}$.

\section{References}

1. Standing, G. (2011). The Precariat: The New Dangerous Class. London: Bloomsbury Academic, 198.

2. Bourdieu, P. (2000). Acts of Resistance. Against the New Myths of our Time. Cambridge: Polity Press, 108.

3. Greer, I. (2016). Welfare reform, precarity and the re-commodification of labour. Work, Employment \& Society, 30(1), 162-173. DOI: doi.org/10.1177/0950017015572578.

4. Swider, S. (2017). Informal and precarious work: The precariat and China. Rural China, 14(1), 19-41. DOI: https:// doi.org/10.1163/22136746-01401002.

5. Lee, C. K. (2016). Precarization or Empowerment? Reflections on Recent Labor Unrest in China. Journal of Asian Studies, 75(2), 317-333. DOI: doi.org/10.1017/S0021911815002132.

6. Siegmann, K. A. \& Schiphorst F. (2016). Understanding the globalizing precariat: From informal sector to precarious work. Progress in Development Studies, 16(2), 111-123. DOI: doi.org/10.1177/1464993415623118.

7. Lazar, S. \& Sanchez, A. (2019). Understanding labour politics in an age of precarity. Dialectical Anthropology, 43(1), 3-14. DOI: doi.org/10.1007/s10624-019-09544-7.

8. Standing, G. (2014). Understanding the precariat through labour and work. Development and Change, 45(5), 963980. DOI: doi.org/10.1111/dech.12120.

9. Courtois, A. \& O'Keefe, T. (2015). Precarity in the ivory cage: Neoliberalism and casualisation of work in the Irish higher education sector. Journal for Critical Education Policy Studies, 13(1), 43-66.

10. Bunnell, T. (2015). Teachers in international schools: a global educational 'precariat'? Globalisation, Societies and Education, 14(4), 543-559. DOI: doi.org/10.1080/14767724.2015.1068163.

11. Doherty, C. (2016). Edufare for the future precariat: the moral agenda in Australia's 'earning or learning' policy. Journal of Education Policy, 32(1), 34-47. DOI: doi.org/10.1080/02680939.2016.1215534.

12. Armano, E. \& Murgia, A. (2013). The precariousnesses of young knowledge workers: A subject-oriented approach. Global Discourse, 3(3-4), 486-501. DOI: doi.org/10.1080/23269995.2013.865313.

13. Hua, J. \& Ray, K. (2017). Beyond the precariat: race, gender, and labor in the taxi and Uber economy. Social Identities, 24(2), 271-289. DOI: doi.org/10.1080/13504630.2017.1321721.

14. Agergaard, S. \& Ungruhe, C. (2016). Ambivalent Precarity: Career Trajectories and Temporalities in Highly Skilled Sports Labor Migration from West Africa to Northern Europe. Anthropology of Work Review, 37(2), 67-78. DOI: 10.1111/ awr.12096.

15. Toshchenko, Zh. N. (2015). Precarlat - A new social class. Sotsiologicheskie issledovaniya [Sociological studies], 6, 3-13. (In Russ.)

16. Volchik, V., Klimenko, L. \& Posukhova, O. (2018). Socio-economic sustainable development and the precariat: A case study of three Russian cities. Entrepreneurship and Sustainability Issues, 6(1), 411-428. DOI: doi.org/10.9770/ jesi.2018.6.1(25). 
17. Shkaratan, O. I., Karacharovskiy, V. V. \& Gasiukova, E. N. (2015). Precariat: Theory and empirical analysis (polls in Russia, 1994-2013 data). Sotsiologicheskie issledovaniya [Sociological studies], 12, 99-110. (In Russ.)

18. Bobkov V. N., Kvachev, V. G., Loktyukhina, N. V. \& Ricceri, M. (2017). Criteria, Probability and Degree of Instability of Employment Taking into Account the Features of the Russian Labour Market. Ekonomika regiona [Economy of Region], 13(3), 672-683. DOI: 10.17059/2017-3-3 (In Russ.)

19. Bender, K. A. \& Roche, K. (2013). Educational mismatch and self-employment. Economics of Education Review, 34, 85-95. DOI: 10.1016/j.econedurev.2013.01.010.

20. Merenkov, A. V., Sandler, D. G. \& Shavrin, V.S. (2019). The features of changes in orientations to employment among bachelor's graduates. Obrazovanie i nauka [The education and science journal], 21(10), 116-142. DOI: https://doi. org/10.17853/1994-5639-2019-10-116-142. (In Russ.)

21. Toshchenko, Zh. T. (Ed.). (2020). Precariat: the emergence of a new class (collective monograph). Moscow: Center for Social Forecasting and Marketing, 400. (In Russ.)

22. Florida R. (2016). The Rise of the Creative Class: And How It's Transforming Work, Leisure and Everyday Life [Kreativnyy klass: Lyudi, kotorye sozdayut budushchee]. Trans. from English. Moscow: Mann, Ivanov and Ferber, 384. (In Russ.)

23. Kotova, S. I. (2017). Precarization of the labor market - a challenge to the economy of labor law? Ekonomika i Zhizn [Economics and Life], 41(992). Retrieved from: https://www.eg-online.ru/article/357991/ (Date of access: 11.08.2020). (In Russ.)

24. Rudakov, V. \& Roshchin, S. (2019). The impact of student academic achievement on graduate salaries: the case of a leading Russian university. Journal of Education and Work, 32(2), 156-180. DOI: 10.1080/13639080.2019.1617839.

25. Pavlova, O. N., Kazin, F. A. \& Butakov, N. A. (2017). Profile-relevant employability of university graduates: social network data analysis. Universitetskoe upravlenie: praktika i analiz [University management: practice and analysis], 21(3(109)), 38-56. DOI: 10.15826/umpa.2017.03.036. (In Russ.)

26. Vasiliev, K., Roshchin, S., Maltseva, I. O., Travkin, P. V., Lukiyanova, A., Chugunov, D., Shulga, I., Rutkowski, J. J., Cahu, P. M., Nellemann, S. (2013). Developing skills for innovative growth in the Russian Federation. Washington: World Bank, 150.

\section{Информация об авторах}

Кокшаров Виктор Анатольевич — кандидат исторических наук, ректор, ведущий научный сотрудник, Научноисследовательская лаборатория по проблемам университетского развития, Уральский федеральный университет имени первого Президента России Б. Н. Ельцина (Российская Федерация, 620002, Екатеринбург, ул. Мира 19; е-таil: v.a.koksharov@urfu.ru).

Агарков Гавриил Александрович - доктор экономических наук, заведующий лабораторией, Научноисследовательская лаборатория по проблемам университетского развития, Уральский федеральный университет имени первого Президента России Б. Н. Ельцина (Российская Федерация, 620002, Екатеринбург, ул. Мира 19; е-таil: g.a.agarkov@urfu.ru).

Сущенко Анастасия Дмитриевна - кандидат социологических наук, старший научный сотрудник, Научноисследовательская лаборатория по проблемам университетского развития, Уральский федеральный университет имени первого Президента России Б. Н. Ельцина (Российская Федерация, 620002, Екатеринбург, ул. Мира 19; е-таil: a.d.sushchenko@urfu.ru).

\section{About the Authors}

Viktor A. Koksharov - Cand. Sci. (Hist.), Rector, Leading Research Associate, Research Laboratory of University Development Problems, Ural Federal University (19, Mira St., Ekaterinburg, 620002, Russian Federation; e-mail: v.a.koksharov@urfu.ru).

Gavriil A. Agarkov - Dr. Sci. (Econ.), Head of Laboratory, Research Laboratory of University Development Problems, Ural Federal University; http://orcid.org/0000-0002-6533-3557 (19, Mira St., Ekaterinburg, 620002, Russian Federation; e-mail: g.a.agarkov@urfu.ru).

Anastasia D. Sushchenko - Cand. Sci. (Soc.), Senior Research Associate, Research Laboratory of University Development Problems, Ural Federal University; http://orcid.org/ 0000-0003-0273-4422 (19, Mira St., Ekaterinburg, 620002, Russian Federation; e-mail: a.d.sushchenko@urfu.ru).

Дата поступления рукописи: 01.04.2020.

Прошла рецензирование: 01.06.2020.

Принято решение о публикации: 15.09.2020.

Received: 20 Apr 2020. Reviewed: 01 Jun 2020. Accepted: 15 Sep 2020. 